\title{
Spray Forming of al Alloys: Experiment and Theory
}

\author{
Georgios S. E. Antipas \\ School of Mining Engineering and Metallurgy, National Technical University of Athens, \\ Zografou Campus, 15780, Athens, Greece
}

Received: August 24, 2011; Revised: December 17, 2011

\begin{abstract}
Close coupled gas atomization has been studied. Pitot tube gas flow measurements support a postulate of transition from an initial sonic to a supersonic and a final sonic state along the convergence region of the jets. Predictions of the $\mathrm{d}_{50}$ median diameter utilizing a two phase model for primary and secondary break up correlate strongly with experimental results from He-atomized $\mathrm{Al}$ alloys by a factor of 0.8216 .
\end{abstract}

Keywords: al alloys, gas atomization, spray forming, two phase flow, liquid break up, surface wave formation

\section{Introduction}

In gas atomization a liquid metal stream is perturbed by a number of high velocity gas jets and is broken up into fine drops ${ }^{1}$ which solidify in flight. In the first stage, that of primary atomization, the surface of the melt is disturbed by a sinusoidal oscillation ${ }^{2}$ and is subsequently broken up into large drops or unstable bodies, the ligaments ${ }^{3}$. During the subsequent stage of secondary atomization, the drops/ ligaments may further disintegrate in flight, either via a lowturbulence mechanism ${ }^{4}$ or in a more chaotic high-turbulence stripping fashion ${ }^{5}$. In spray deposition the particles inside the atomization spray are allowed to impinge on a substrate positioned at a certain distance below the point of atomization, producing a preform. Gas flow characteristics at the point of atomization as well as further downstream affect the modes of metal break up and consequently determine the size and mass distribution of the resulting spray. Drop size and mass distribution, two-phase turbulence effects and heat transfer during solidification in turn determine the metallurgical quality of the preform. Preform quality factors include the level of porosity, the grain size and the distribution of intermetallic phases. Atomization process control has been considered in earlier phenomenological studies $^{6-14}$ in respect to atomization parameters - such as nature of the gas and melt phase, gas injection pressures and melt superheat. More recently, experimental treatises of atomizing geometries have been presented ${ }^{15-17}$. Solidification modeling and process control frequently rely on powder size calculated from empirical equations, e.g. the Lubanska equation $^{31}$. However, such empirical equations do not yield drop size or mass distributions inside the spray cone. Liquid break up phenomena - although described in the macro scale early on ${ }^{18-21}$ - have not been reflected on rigorous modelling implementations. Modern atomization modeling appears to be focusing on CPU-intensive stochastic simulation of the liquid jet and primary atomization in terms of Reynoldsaveraged Navier-Stokes mixing ${ }^{22}$. Recently, the more

*e-mail: gantipas@metal.ntua.gr realistic cases of turbulent atomization conditions have been addressed, e.g. by $\mathrm{CFD}^{23-25}$ and integrated models ${ }^{17,34}$ have been proposed.

This study considers the case of close coupled atomization of $\mathrm{Al}$ alloys and builds upon a theoretical two-phase model for melt fragmentation ${ }^{32}$. The gas phase produced by the atomizer is recorded by Pitot tube pressure measurements of Argon and Nitrogen flows and tested against model predictions. The model yields powder size and mass distributions and is compared to close coupled atomization data of $\mathrm{Al}$ alloys.

\section{Experimental}

A number of Al alloys were spray formed by Helium. The atomization conditions are presented in Table 1 and the atomizer configuration used is shown in Figure 1. The melt was delivered via a tube of diameter $\mathrm{D}_{\mathrm{m}}$, normally equal to $2 \mathrm{~mm}$. The atomizing gas was fed through inclined jet nozzles arranged in a ring configuration (eighteen such nozzles are considered in this paper). The internal diameter and angle of inclination of each gas jet was $0.75 \mathrm{~mm}$ and $20^{\circ}$ respectively. Geometry indicates that the point of initial atomization is located approximately $7 \mathrm{~mm}$ downstream the tip of the melt tube. Figure 2 is a schematic diagram of the geometry of the die and of the generated flow.

The atomized melt was deposited onto a copper substrate able to move along the vertical direction of the spray forming assembly. At the end of each experiment, the overspray, i.e. the powder that did not impact on the substrate, was collected and sieved. A few grams of the of the sub- $200 \mu \mathrm{m}$ spray fraction for every run were dispersed in water containing a drop of Nonidet P42 dispersant and agitated in an ultrasonic bath for 5 minutes to reduce particle agglomeration. The $\mathrm{d}_{50}$ mass median diameter was then estimated from the cumulative particle size distribution obtained via analysis by a Malvern Master Sizer. 
Table 1. Experimentally measured and model predicted values of mass median $\mathrm{d}_{50}$.

\begin{tabular}{|c|c|c|c|c|c|c|}
\hline Alloy & $\begin{array}{c}\text { Atomizing } \\
\text { pressure (MPa) }\end{array}$ & $\begin{array}{c}\text { Gas to melt } \\
\text { mass flux }\end{array}$ & $\begin{array}{c}\text { Melt tube } \\
\text { diameter }(\mathrm{mm})\end{array}$ & $\begin{array}{c}\text { Measured } d_{50} \\
(\mu \mathrm{m})\end{array}$ & $\begin{array}{l}\text { Model d } \\
\quad(\mu \mathrm{m})\end{array}$ & $\begin{array}{c}\text { Lubanska } \mathbf{d}_{\mathrm{m}} \\
(\mu \mathbf{m})\end{array}$ \\
\hline Al-Cr-Hf & 0.86 & 0.59 & 2.00 & 20.98 & 20.54 & 20.85 \\
\hline $\mathrm{Al}-\mathrm{Cr}-\mathrm{Fe}$ & 1.03 & 0.59 & 2.00 & 34.94 & 28.50 & 20.80 \\
\hline Al-Fe-V-Si & 1.03 & 0.63 & 2.00 & 25.79 & 28.50 & 19.34 \\
\hline $\mathrm{Al}-\mathrm{Si}-\mathrm{Cu}$ & 1.03 & 0.72 & 2.00 & 18.77 & 22.80 & 20.29 \\
\hline Al-Cr-Hf & 1.03 & 0.76 & 2.00 & 25.35 & 23.00 & 18.86 \\
\hline $\mathrm{Al}-\mathrm{Cr}$ & 1.03 & 0.80 & 2.00 & 23.39 & 23.05 & 18.46 \\
\hline $\mathrm{Al}-\mathrm{Cr}$ & 1.21 & 0.85 & 2.00 & 22.67 & 24.20 & 18.10 \\
\hline Al-Fe-V-Si & 1.03 & 1.10 & 2.00 & 18.85 & 20.60 & 16.49 \\
\hline $\mathrm{Al}$ & 1.72 & 1.23 & 2.00 & 28.01 & 28.35 & 15.84 \\
\hline $\mathrm{Al}$ & 1.03 & 1.70 & 2.10 & 24.11 & 22.15 & 14.23 \\
\hline $\mathrm{Al}-\mathrm{Fe}$ & 3.62 & 2.44 & 2.01 & 34.95 & 31.56 & 12.94 \\
\hline $\mathrm{Al}$ & 1.38 & 3.25 & 1.50 & 16.89 & 24.00 & 12.13 \\
\hline Al-Li-Hf & 1.03 & 3.57 & 2.00 & 17.56 & 21.90 & 11.85 \\
\hline
\end{tabular}

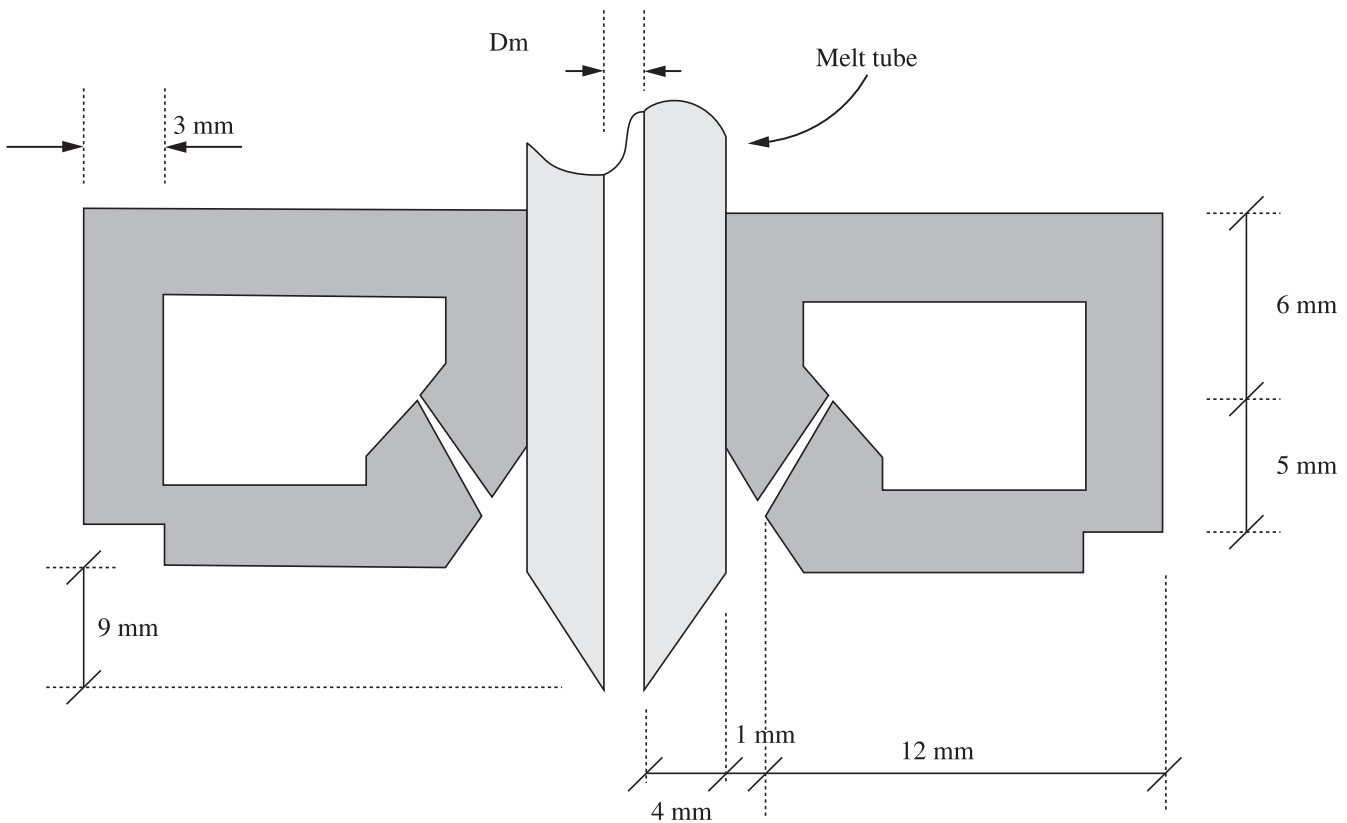

Figure 1. Configuration of the atomizing die.

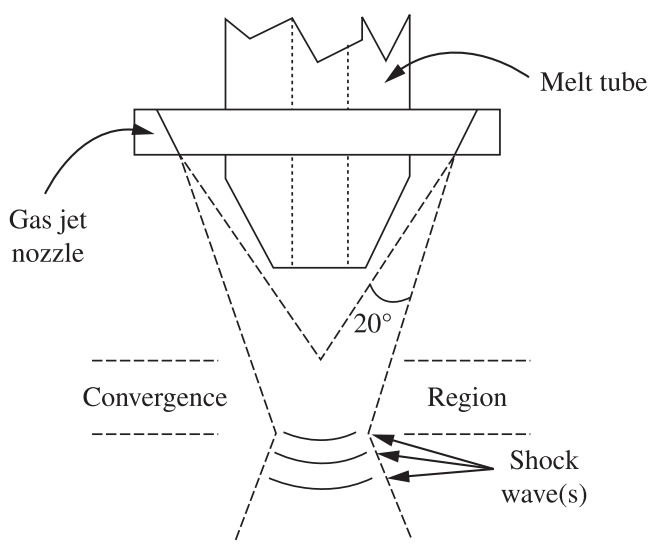

Figure 2. Convergence of the gas jets.

\subsection{Experimental evaluation of gas velocities}

Pitot tube gas pressure measurements were recorded. The diameter of the tube head was $2 \mathrm{~mm}$. The measurements were taken along the central axis of the jet formed below the convergence region. During this study no melt phase was used and measurements were made for Argon and Nitrogen injected by the atomizer at a back pressure of 0.69 MPa. Evaluation of gas velocities from the measured pressures took into account compressibility of the gas phase ${ }^{26}$.

\section{Theoretical Model}

In order to simulate the gas flow produced by the atomizer, a model ${ }^{33}$ was developed for which input parameters were the initial conditions of the gas phase (temperature, pressure, and density), the atomization 
pressure and the geometric characteristics of the die. The model takes into account the flow characteristics upstream and downstream as well as within the convergence region. An analytical expression by Szekely ${ }^{27}$ was employed to simulate the gas flow below convergence. In Szekely's empirical derivation, the expressions for the axial, $U_{z}$, and radial, $\mathrm{U}_{\mathrm{r}}$, components of gas velocity are (Equations $1 \mathrm{a}, \mathrm{b}$ ):

$$
\begin{aligned}
& U_{z}=2.36 \sqrt{\frac{J_{z}}{\rho_{g}}} \frac{1}{z\left(1+0.25 n^{2}\right)^{2}} \\
& U_{r}=\sqrt{\frac{3 J_{z}}{\pi \rho_{g}}} \frac{n-0.25 n^{2}}{x\left(1+0.25 n^{2}\right)^{2}}
\end{aligned}
$$

where $\mathrm{n}=15.18 \mathrm{r} / \mathrm{z}, \mathrm{z}$ and $\mathrm{r}$ are the axial and radial distance from the origin of the jet respectively, $\mathrm{J}_{\mathrm{z}}$ is the momentum flowrate of the jet and $\rho_{g}$ is the gas density. Figure 3 shows the measured central axis velocity components for the flows of Nitrogen and Argon injected at a pressure of 0.69 $\mathrm{MPa}$, against the predictions of the current model. As can be seen, the agreement is satisfactory and strongly suggests that the gas flow downstream the convergence area behaves in a manner similar to that of a single turbulent free jet.

\subsection{Calculation of particle velocity profiles}

Particle tracking inside the flow was performed in a Lagrangian fashion. The forces considered to act upon the drops were the drag force due to the velocity difference between the gas and liquid phase and the gravitational force for a particle of mass $m_{p}$ (Equation 2):

$$
m_{\rho} \frac{d U_{p}}{d t}=\frac{1}{2} C D \rho g U_{d}^{2} A+m_{p} g
$$

where $U_{p}$ is the velocity of the particle, $C_{d}$ is the drag coefficient $^{27}, \rho_{g}$ is the gas density, $U_{d}$ is the relative velocity between the gas phase and the particle, $\mathrm{A}$ is the area of the particle seen by the gas flow and $\mathrm{g}$ is the gravitational acceleration. The velocities of aluminium droplets of varying diameters were calculated, assuming no break up modes and no solidification of the melt.

\subsection{Primary and secondary break up}

A summary of the basic fragmentation mechanisms involved in atomization is given by Burger ${ }^{28}$. A linear analog of the fragmentation process is based on work concerning the wind-induced surface waves on liquid bodies. An original study by Squire ${ }^{29}$ is an example of the early efforts to correlate surface instabilities to the gas phase flowing parallel to the free surface of a liquid film. Following basic wave mechanics, Squire in this linearized approach considered antisymmetric traveling waves which followed an exponential growth mode. The wave with the largest growth rate was calculated and the subsequent break up history of the liquid film was assumed to depend on that, in spite of the fact that the gas phase yields an array of different wavelengths and growth rates. In this derivation liquid viscosity was not taken into account. In addition, gas components normal to the free liquid surface

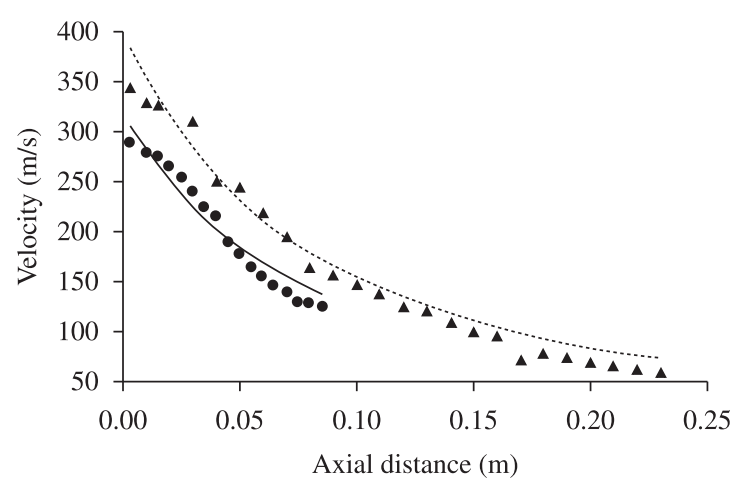

\begin{tabular}{|ll|}
\hline - Argon 100 psi & - Argon - model \\
^ Nitrogen 100 psi & -..... Nitrogen - model
\end{tabular}

Figure 3. Pitot tube measurements and model prediction of gas velocities.

as well as gas compressibility were not considered. A somewhat different approach of the same problem was that of Bradley ${ }^{30}$. He considered the Navier-Stokes equations for the wave disturbance as well as the continuity equation and taking into account the compressibility of the gas phase, he solved this system for the overall pressure exerted on an infinitesimal displacement of the liquid surface. His work yielded a criterion for the growth of a sinusoidal traveling wave as well as the wavelength having the maximum growth rate which was assumed to dominate break up.

In the current work, the wave mechanism of primary disintegration is based on the surface wave formation theory as formulated by Antipas ${ }^{32}$. The model considers a fastest growing wavelength to be responsible for the primary deformation of the melt stream. The popular assumption of a single wavelength is followed here and every other wavelength that is probable to rise out of the same flow conditions is neglected. The gas velocity responsible for atomization is taken as the sonic velocity of the gas jets. After determining the fastest growing wavelength the crests and troughs of the liquid column are monitored with time, allowing for the fact that the wave has a phase (propagation) velocity downstream. When the crests reach a certain height stripping of a part of the crest leads to the formation of an unstable ligament. Due to the inherent cylindrical symmetry of this approach the ligament itself has the shape of a ring. Unlike similar approaches in the past, the current model does not nominate a basic amplitude above which shedding of the ligaments commences. Instead, it utilizes a force balance criterion to calculate the critical amplitude for specific gas and metal properties above which stripping of the tip of the crest occurs. In this way, the fastest growing wavelength is related to a critical amplitude and for every crest with an amplitude exceeding the critical one, the diameter and volume of the ring-shaped ligament are determined.

The model of secondary break up - i.e. disintegration of the ligament into smaller fragments - is also based on the Kelvin-Helmholtz theory. It assumes a cylindrical shape of the ligament or drop rather than a spherical one, to facilitate the computations. The volume and radius of 
the cylinder are taken to be the same as those of the drop. Rather than utilizing a basic fastest growing wavelength to displace the liquid surface, a wide array of wavelengths (and their corresponding growth rates) are considered. The lower and upper limits of such an array are determined from the analysis by Antipas ${ }^{32}$ taking into account that in this particular case the gravity field lies in the same direction as the liquid flow. In the modeling of the secondary breakup the drops change velocity as they move inside the flow field and reduce in size during fragmentation.

\section{Results and Discussion}

The maximum velocities measured for both Argon and Nitrogen on the central axis of the jet (just below convergence) approximated the sonic velocities of a flow having undergone the transition from supersonic to sonic condition, via a succession of shock waves ${ }^{33}$ as shown in Figure 2. This enabled the indirect calculation of the diameter of the convergence region, which was found to be approximately equal to $4 \mathrm{~mm}$ for both flows. Gas velocities derived from Pitot pressure measurements and comparisons against the model are shown in Figure 3. There is tight agreement between experiment and theory, with correlation coefficients for Argon equal to 0.9816 and for Nitrogen equal to 0.9895 . Drop trajectories are presented in Figure 4. They indicate that smaller drops, e.g. $1 \mu \mathrm{m}$ in diameter, exhibit a tendency to follow the gas velocity component closely. Thus for small diameters there is an insignificantly small relative velocity between the gas and metal phase which in turn makes secondary breakup of such a fragment unlikely. As one considers larger fragments, the drop inertia takes over its motion and it follows that the larger the drop the slower is its response to excitation caused by the gas forces. At the same time, as drop size increases so does the time span in which the relative velocity between the two faces is adequately large to cause break up. Spray forming experimental data various $\mathrm{Al}$ alloys atomized by Helium in the assembly shown in Figure 1 are presented in Table 1. A comparison of these experimental data with the theory is shown in Figure 5, in which superimposed are predictions of the Lubanska equation. The size of merit in Figure 5 is the mass median diameter, $\mathrm{d}_{50}$, defined as the drop size below which lies 50 per cent of the total mass of the spray. For completeness, we note that the Lubanska equation is defined as (Equation 3):

$d_{m}=D_{m} K \sqrt{\frac{v_{m}}{v_{g} W}\left(1+\frac{M}{A}\right)}$

where $\mathrm{D}_{\mathrm{m}}$ is the diameter of the liquid metal stream (Figure 1), $\mathrm{K}$ is a constant varying in from 40 to $50^{[31]}, \mathrm{v}_{\mathrm{m}}$ and $v_{\mathrm{g}}$ are the kinematic viscosity of the liquid metal and gas phase respectively, $W=\rho_{1} U^{2} D_{m} / \gamma$ is the Weber number, $\rho_{1}$ and $\gamma$ are the liquid metal density and surface tension respectively, $\mathrm{U}$ is the gas velocity upon impact on the liquid stream and $\mathrm{M}$ and $\mathrm{A}$ are the metal and gas mass flow rates respectively. The results of the model together with the predictions of Equation 3 are also presented Table 1. The correlation coefficient between experimental spray

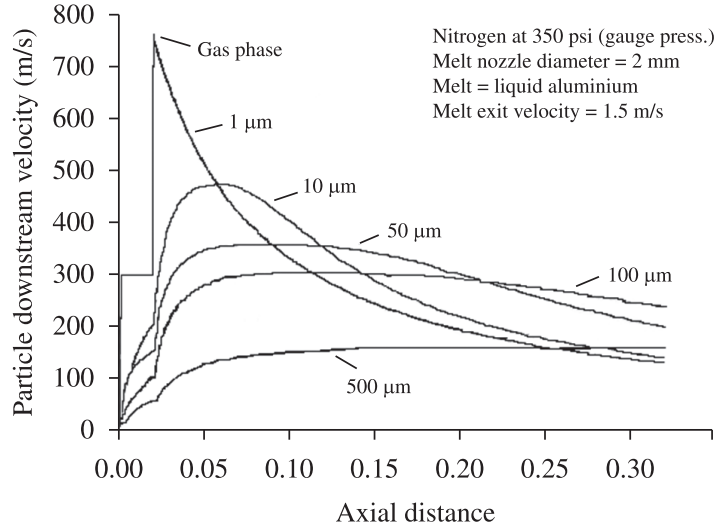

Figure 4. Model prediction of particle velocity histories.

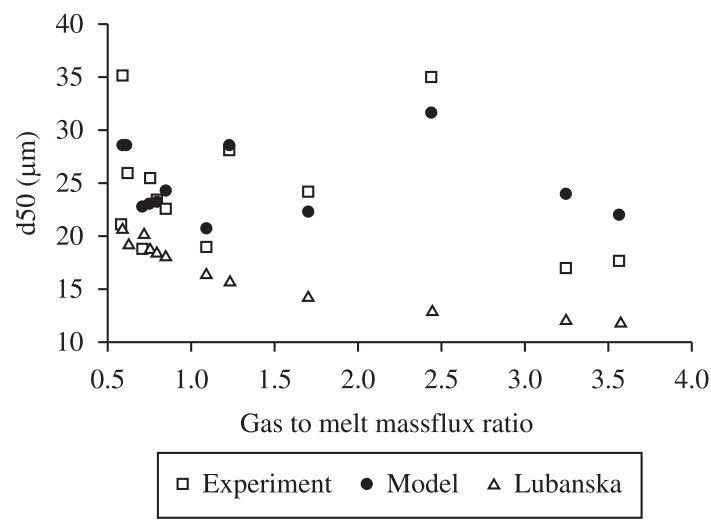

Figure 5. Experimental results and predictions of the mass median size $d_{50}$.

forming data and the Lubanska equation is 0.1646 while the theoretical model correlates in particularly tight agreement by a factor of 0.8216 .

\section{Conclusions}

A number of $\mathrm{Al}$ alloys were spray formed by Helium in a variety of conditions in a close coupled atomizer. Pitot tube experiments of the gas flow induced by the coupled atomizer indicated that there is a transition from an initially sonic to a supersonic and a final sonic state of the flow along the convergence region of the gas jets. Based on the Kelvin-Helmholtz stability theory, a model describing primary and secondary breakup was formulated. The model was coupled with gas and melt phase velocity predictions and was compared against spray forming experimental data. The simulated $d_{50}$ mass median diameter compares favorably with experiment and lies in better agreement than the corresponding predictions based on the Lubanska equation for all sets of the atomizing conditions studied.

\section{Acknowledgements}

The author gratefully acknowledges the provision of experimental facilities by the Department of Materials Science and Engineering, University of Surrey, UK. 


\section{References}

1. Dumouchel C, Cousin J and Triballier K. Experimental analysis of liquid-gas interface at low Weber number: interface length and fractal dimension. Experiments in Fluids. 2005; 39(4):651-666. http://dx.doi.org/10.1007/s00348-005-1005-5

2. Fei L, Xu S and Huang S. Relaxation and breakup of a cylindrical liquid column. Science in China Series E: Technological Sciences. 2008; 51(2):145-152. http://dx.doi. org/10.1007/s11431-008-0018-8

3. Shinjo $\mathbf{J}$ and Umemura A. Simulation of liquid jet primary breakup: Dynamics of ligament and droplet formation. International Journal of Multiphase Flow. 2010; 36(7):513-532. http://dx.doi.org/10.1016/j.ijmultiphaseflow.2010.03.008

4. $\mathrm{Ng} \mathrm{CL}$, Sankarakrishnana R and Sallam KA. Bag breakup of nonturbulent liquid jets in crossflow. International Journal of Multiphase Flow. 2008; 34(3):241-259. http://dx.doi. org/10.1016/j.jimultiphaseflow.2007.07.005

5. Guildenbecher DR, López-Rivera C and Sojka PE. Secondary atomization. Experiments in Fluids. 2009; 46(3):371-402. http://dx.doi.org/10.1007/s00348-008-0593-2

6. See J and Johnston G. Interactions Between Nitrogen Jets and Liquid Lead and Tin Streams. Powder Technology. 1978; 21:119-133. http://dx.doi.org/10.1016/0032-5910(78)80115-6

7. Kim M and Jones H. Effect of Process Variables in GasJet Atomization and Production of Multilayer Deposits. In: Proceedings of the 4th International Conference on Rapidly Quenched Metals; 1981; Sendai. Japan Institute of Metals; 1981. p.85-88.

8. Hiroyasu H, Shimizu M and Arai M. The Breakup of a High Speed Jet in a High Pressure Gaseous Atmosphere. In: Proceedings of the 4th International Conference on Liquid Atomization and Spray Systems - ICLASS-82; 1982; Madison. ICLASS; 1982. p. 69-74.

9. Pai B and Nijaguna B. The Charecterization of Sprays. In: Proceedings of the 4th International Conference on Liquid Atomization and Spray Systems - ICLASS-82; 1982; Madison. ICLASS; 1982. p. 29-35.

10. Reitz R. Modelling Atomization Processes in HighPressure Vaporizing Sprays. Atomization and Spray Technology. 1987; 3:309-337.

11. Arai M, Shimizu M and Hiroyasu H. Break-Up Length and Spray Formation Mechanism of a High Speed Liquid Jet. In: Proceedings of the International Conference on Liquid Atomization and Spray Systems - ICLASS-88; 1988; Sendai. ICLASS; 1988. p.177-184.

12. Ünal A. Effect of Processing Variables on Particle Size in Gas Atomization of Rapidly Solidified Aluminium Powders. Materials Science and Technology. 1987; 3:1029-1039.

13. Ingebo R. Experimental and Theoretical Effects of Nitrogen Gas Flow Rate on Liquid -Jet Atomization. Journal of Propulsion and Power. 1988; 4(5):406-411. http://dx.doi. org/10.2514/3.23081

14. Zanelli S. Behaviour of a Liquid Jet Near the Nozzle. In: Proceedings of the International Conference on Liquid Atomization and Spray Systems - ICLASS-88; 1988; Sendai. ICLASS; 1988. p.1-14.

15. Vahedi Tafreshi H and Pourdeyhimi B. The effects of nozzle geometry on water jet breakup at high Reynolds numbers. Experiments in Fluids. 2003; 35(4):364-371. http://dx.doi. org/10.1007/s00348-003-0685-y

16. Vukasinovic B, Smith MK and Glezer A. Mechanisms of freesurface breakup in vibration-induced liquid atomization. Physics of Fluids. 2007; 19(1). http://dx.doi.org/10.1063/1.2434799
17. Dumouchel C. On the experimental investigation on primary atomization of liquid streams. Experiments in Fluids. 2008; 45(3):371-422. http://dx.doi.org/10.1007/s00348-0080526-0

18. Hinze J. Fundamentals of the Hydrodynamic Mechanism of Splitting in Dispersion Processes. AIChE Journal. 1955; 1(3):289-295. http://dx.doi.org/10.1002/aic.690010303

19. Gordon G. Mechanism and Speed of Breakup of Drops. Journal of Applied Physics. 1959; 30(11):1759-1761. http://dx.doi. org/10.1063/1.1735050

20. Mehrota S. Mathematical Modelling of Gas Atomization Process for Metal Powder Production. Powder Metallurgy International. 1988; 13(2):80-84.

21. Haas F. Stability of Droplets Suddenly Exposed to a High Velocity Gas Stream. AIChE Journal. 1964; 10(6):920-924. http://dx.doi.org/10.1002/aic.690100627

22. Gorokhovski M and Herrmann M. Modeling Primary Atomization. Annual Review of Fluid Mechanics. 2008; 40:343-366. http://dx.doi.org/10.1146/annurev. fluid.40.111406.102200

23. Ishimoto J, Ohira K, Okabayashi K and Chitose K. Integrated numerical prediction of atomization process of liquid hydrogen jet. Cryogenics. 2008; 48(5-6):238-247. http://dx.doi. org/10.1016/j.cryogenics.2008.03.006

24. Trinh HP, Chen CP and Balasubramanyam MS. Numerical Simulation of Liquid Jet Atomization Including Turbulence Effects. Journal of Engineering for Gas Turbines and Power. 2007; 129(4):920-928. http://dx.doi. org/10.1115/1.2747253

25. Pougatcha K, Salcudeana M, Chanb E and Knapper B. A twofluid model of gas-assisted atomization including flow through the nozzle, phase inversion, and spray dispersion. International Journal of Multiphase Flow. 2009; 35(7):661-675. http://dx.doi.org/10.1016/j.ijmultiphaseflow.2009.03.001

26. Roberson JA and Crowe CT. Engineering Fluid Mechanics. Boston: Houghton Mifflin Co; 1975.

27. Szekely J. Fluid Flow Phenomena in Metals Processing. London: Academic Press; 1979.

28. Burger M, Berg E, Cho SH and Schatz A. Fragmentation processes in gas and water atomization plants for process optimization purposes. I. Discussion of the main fragmentation processes. Powder Metallurgy International. 1989; 21(6):10-5.

29. Squire HB. Investigation of the instability of a moving liquid film. British Journal of Applied Physics. 1953; 4:167-169. http://dx.doi.org/10.1088/0508-3443/4/6/302

30. Bradley $\mathrm{D}$. On the atomization of a liquid by high-velocity gases: II. Journal of Physics D: Applied Physics. 1973; 6:724-736. 2267-2272.

31. Lubanska H. Correction of Spray Ring Data for Gas Atomization of Liquid Metals February. Journal of Metals. 1970; 22:45-49.

32. Antipas GSE. Modelling of the Break Up Mechanism in Gas Atomization of Liquid Metals, Part I. The Surface Wave Formation Model. Computational Materials Science. 2006; 35:416-422. http://dx.doi.org/10.1016/j. commatsci.2005.03.009

33. Antipas GSE. Modelling of the Break Up Mechanism in Gas Atomization of Liquid Metals, Part II. The Gas Flow Model. Computational Materials Science. 2009; 46:955-59. http://dx.doi.org/10.1016/j.commatsci.2009.04.046

34. Kumar A, Ghosh S and Dhindaw BK. Simulation of cooling of liquid Al-33 wt.\% Cu droplet impinging on a metallic substrate and its experimental validation. Acta Materialia. 2010; 58:122-133. http://dx.doi.org/10.1016/j.actamat.2009.08.063 